\title{
Soil electrical conductivity estimated by time domain reflectometry and electromagnetic induction sensors: Accounting for the different sensor observation volumes
}

\author{
Ali Saeed, ${ }^{1}$ Alessandro Comegna, ${ }^{1}$ Giovanna Dragonetti, ${ }^{2}$ Nicola Lamaddalena, ${ }^{2}$ Angelo Sommella, ${ }^{3}$ \\ Antonio Coppola ${ }^{1}$ \\ ${ }^{1}$ School of Agricultural, Forestry, Food and Environmental Sciences, University of Basilicata, Potenza; ${ }^{2}$ Land and \\ Water Division, Mediterranean Agronomic Institute - International Centre for Advanced Mediterranean Agronomic \\ Studies, Bari; ${ }^{3}$ Department of Agriculture, Federico II University, Naples, Italy
}

\begin{abstract}
This paper dealt with the calibration of an EMI sensor for monitoring the time dynamics of root zone salinity under irrigation with saline water. Calibration was based on an empirical multiple regression approach largely adopted in the past and still applied in practice for its relative simplicity. Compared to the more complex inversion approaches, it requires an independent dataset of local $\sigma_{\mathrm{b}}$ measured within discrete depth intervals, to be compared to horizontal and vertical electrical conductivity $\left(\mathrm{EC}_{\mathrm{a}} \mathrm{H}\right.$ and $\mathrm{EC}_{\mathrm{a}} \mathrm{V}$ ) readings for estimating the parameters of the empirical regression equations. In this paper, we used time domain reflectometry (TDR) readings to replace direct sampling for these local $\sigma_{b}$ measurements. When using this approach, there is the important issue of taking into account the effect of the different sensor observation volumes, making the readings not immediately comparable for empirical calibration. Accordingly, a classical Fourier's filtering technique was applied to remove the high frequency part (at small spatial scale) of the original data variability, which, due to the different observation volume, was the main source of dissimilarity between the two datasets. Thus, calibration focused only on the lower frequency information, that is, the information at a spatial scale larger than the observation volume of the
\end{abstract}

Correspondence: Antonio Coppola, School of Agricultural, Forestry, Food and Environmental Sciences (SAFE), University of Basilicata, 85100 Potenza, Italy.

E-mail: antonio.coppola@unibas.it

Key words: Soil salinity; electromagnetic induction; time domain reflectometry; sensors observation volume; Fourier's analysis.

See online Appendix for additional Equations.

Received for publication: 10 May 2017.

Accepted for publication: 2 August 2017.

(C) Copyright A. Saeed et al., 2017

Licensee PAGEPress, Italy

Journal of Agricultural Engineering 2017; XLVIII:716

doi:10.4081/jae.2017.716

This article is distributed under the terms of the Creative Commons Attribution Noncommercial License (by-nc 4.0) which permits any noncommercial use, distribution, and reproduction in any medium, provided the original author(s) and source are credited. sensors. By this analysis, we showed and quantified the degree to which the information of the set of TDR readings came from a combination of local and larger scale heterogeneities and how they have to be manipulated for use in EMI electromagnetic induction sensor calibration.

\section{Introduction}

Saline irrigation water management requires regular monitoring of the horizontal/vertical distribution of salts, as well as their temporal evolution, in the rather shallow soil layer explored by roots. The salt distribution in the root zone depends, besides salinity of irrigation water, management practices and other environmental factors, on the complex non-linear processes of water flow and solute transport in soil inducing variable distributions and storage of solutes and water along the soil profile.

Root zone soil salinity has traditionally been assessed using destructive soil sampling to determine the electrical conductivity of a water-saturated soil paste in the laboratory. Using this technique for salinity monitoring over large areas is obviously expensive and time consuming and thus rather disused.

To overcome the limitations of traditional soil sampling, nondestructive methodologies, mostly based on electromagnetic techniques, may be used to evaluate soil salinity directly in the field. Time domain reflectometry (TDR) sensors allow simultaneous measurements of water content, $\theta$, and the bulk electrical conductivity, $\sigma_{\mathrm{b}}$, of the soil volume explored by the probe (Heimovaara et al., 1995; Robinson et al., 2003; Severino et al., 2010; Coppola et $a l ., 2011) . \sigma_{b}$ depends on the water content, $\theta$, the electrical conductivity of the soil solution (the salinity), $\sigma_{\mathrm{W}}$, the tortuosity of the soil pore system, $\tau$, as well as on other factors related to the solid phase such as bulk density, clay content and mineralogy. For a specific soil, TDR sensors may thus be calibrated in the laboratory for estimating $\sigma_{\mathrm{W}}$ (Rhoades and van Schilfgaarde, 1976; Nadler and Frenkel, 1980; Mallants et al., 1996). However, they have a relatively small observation volume and thus only provide localscale measurements (hereafter, with the expression local $\sigma_{b}$ we will refer to the average $\sigma_{b}$ within a discrete depth interval, as that measured on a soil sample or by a TDR probe). Depth distribution of local $\sigma_{b}$ may only be obtained by inserting sensors in the soil at different depths, which still makes the TDR an invasive technique not completely suitable for extensive monitoring and for a complete and rapid coverage of the area of interest.

Compared to TDR, electromagnetic induction (EMI) sensors allow remote (without insertion of sensors into the soil) extensive 
surveys (Rhoades and Oster, 1986; Sudduth et al., 2003; Zhu et al., 2010). EMI sensors give depth-weighted apparent electrical conductivity $\left(\mathrm{EC}_{\mathrm{a}}\right)$ measurements, depending on the specific depth distribution of the $\sigma_{\mathrm{b}}$, as well as on the depth response function of the sensor used (McNeill, 1980). Frequently, most of the salt dynamics during an irrigation season is confined to a surface soil layer, which is thinner than the whole profile depth explored, by an EMI sensor (Coppola et al., 2015, 2016). Deducing the electrical conductivity of the upper layer and, more in general, the depth distribution of the local $\sigma_{b}$ along the soil profile from aboveground $\mathrm{EC}_{\mathrm{a}}$ readings is not a simple task and has been traditionally carried out by two main approaches: i) inverting the signal coming from the EMI sensor; ii) using empirical calibration relations by relating the depth-integrated $\mathrm{EC}_{\mathrm{a}}$ readings to the actual vertical distribution of $\sigma_{\mathrm{b}}$ measured by alternative methods (like TDR probes) within discrete depth intervals.

In the first case, most studies use the linear model proposed by McNeill (1980), describing the relative depth-response of the ground conductivity meter. By using this model, Borchers et al. (1997) implemented a least squares inverse procedure with second order Tikhonov regularization, to estimate $\sigma_{b}$ vertical distribution from EMI field data. More recent studies (Hendrickx et al., 2002; Deidda et al., 2003, 2014), extended the approach to a more complicated non-linear model of the response of a ground conductivity meter to changes with depth of $\sigma_{\mathrm{b}}$. Noteworthy, these inverse procedures are only based on electromagnetic physics. Thus, they are only based on $\mathrm{EC}_{\mathrm{a}}$ readings, possibly taken with both the horizontal and vertical configurations and with the sensor at different heights above the ground, and would not require any further field calibration.

Compared to the EMI signal inversion procedure, the empirical calibration approach requires an independent dataset of local $\sigma_{b}$ measured within discrete depth intervals, to be compared to $\mathrm{EC}_{\mathrm{a}}$ readings for estimating the parameters of the empirical regression equations. For selected monitoring sites, the $\mathrm{EC}_{\mathrm{a}}$ readings, made either at a sequence of heights above the soil surface or only at the soil surface, may be related to local $\sigma_{b}$ measured (for example by TDR) within discrete depth intervals of the soil profile by solving a set of empirical equations containing depth-specific calibration parameters. A multiple linear regression procedure may thus be applied to find the calibration parameters specific for discrete soil layers. TDR probes may be effectively used to replace direct sampling for these local $\sigma_{b}$ measurements.

Different procedures may be found in the literature, looking either for calibration coefficients through multiple regression (Rhoades and Corwin, 1981; Lesch et al., 1992; Triantafilis et al., 2000; Coppola et al., 2016), modelled coefficients (Slavich and Petterson, 1990), theoretical coefficients calculated by using the theoretical EMI depth response functions (Cook and Walker, 1992) or empirical-mathematical coefficients (the so-called established coefficients) (Corwin and Rhoades, 1982, 1984). Of all the approaches above, that proposed by Rhoades and Corwin (1981) is conceptually simple as it is based on multiple $\mathrm{EC}_{\mathrm{a}}$ measurements to be made at a succession of heights above the soil surface for each of the monitoring sites. The technique takes advantage of the fact that a sequence of measurements with different depth weightings enhances the information on the depth distribution of local $\sigma_{b}$. A simplified form of this approach (Corwin and Rhoades, 1982; Rhoades et al., 1989; Triantafilis et al., 2000) uses only surface $\mathrm{EC}_{\mathrm{a}}$ measurements in both horizontal $\left(\mathrm{EC}_{\mathrm{a}} \mathrm{H}\right)$ and vertical $\left(\mathrm{EC}_{\mathrm{a}} \mathrm{V}\right)$ configurations (the procedure used in this paper). Independently on the approach used, inversion or empirical calibration, there are some important problems and drawbacks, which regularly emerge when the $\sigma_{b}$ EMI predictions have to be compared to TDR measurements. One of these issues is related to the fact that EMI sensors and TDR probes (or soil samples) used for measuring the local $\sigma_{b}$ have a significantly different observation volume. This may have important implications for evaluating the predictive effectiveness of the calibrated parameters. Specifically, the measurement volume of an EMI ground conductivity meter $\left(\approx 10^{5} \mathrm{~cm}^{3}\right)$ is much larger than that of a TDR probe $\left(\approx 10^{3} \mathrm{~cm}^{3}\right)$. Besides, an $\mathrm{EC}_{\mathrm{a}}$ measurement is averaged over a lateral area approximately equal to the measurement depth. Because of their relatively lower observation volume, TDR sensors provide quasi-point values and do not integrate the small scale variability of the chemical concentrations in the soil solution (and of the water content) induced by natural soil heterogeneity. Thus, the variability of a set of TDR readings is expected to come from a combination of smaller and larger-scale heterogeneities. By contrast, EMI sensor readings smooth the small-scale variability seen by TDR probes. As a consequence, the variability revealed by a set of EMI and TDR readings, taken at the same sites, may have completely different characteristics: i) the variance of EMI readings is expected to be significantly lower than that of TDR probe measurements; ii) small scale patterns of variability revealed by a set of TDR readings may not be seen by a set of EMI readings in the same sites. At worst, decreasing TDR readings could correspond to increasing EMI values and vice versa (this will be immediately clear in the Results and discussion section). In such a context, the sense of classical site-by-site comparison between EMI and TDR (or in general local scale) measurements for EMI calibration (and validation) is at least questionable (Slater et al., 2000; Oberdörster et al., 2010; Coppola et al., 2016).

There is thus a need for a methodology to be applied preliminarily to make the EMI data and the TDR (or, in general, the local scale) data actually comparable, by highlighting the part of information actually shared by the two data series. This is the main objective of this paper. To do that, we will use an EMI-TDR data set collected at regularly spaced monitoring sites and in several time campaigns along three transects irrigated with water at different salinity levels. After exploring the different patterns of variability of the original EMI and TDR data series, a classical Fourier's analysis will be applied to filter the high frequency part (at small spatial scale) of the original data variability, which, due to the different observation volume, is expected to be the main source of dissimilarity between the patterns of variability of the two datasets. Consequently, the comparison will focus only on the lower frequency information (that is, the information at a spatial scale larger than the observation volume of the sensors). Being detected by both the sensors, the latter should make the two data series actually comparable.

\section{Materials and methods}

\section{Experimental site}

The experiment was carried out in a $500-\mathrm{m}^{2}$ field at the Mediterranean Agronomic Institute of Valenzano, Bari (south-eastern coast of Italy). The area has typically Mediterranean climate with rainy winters and very hot dry summers. The soil is a Colluvic Regosol, consisting of a silty-loam layer of an average depth of 60 $\mathrm{cm}$ on a shallow fractured calcareous rock.

The experimental field consisted of three adjacent transects, 30 $\mathrm{m}$ long and $4.2 \mathrm{~m}$ wide, with a distance between transects of $3.0 \mathrm{~m}$. The three transects were irrigated with water at three different 
salinity levels $\left(1 \mathrm{dSm}^{-1}, 3 \mathrm{dSm}^{-1}, 6 \mathrm{dSm}^{-1}\right)$, hereafter identified as $1 \mathrm{dS}, 3 \mathrm{dS}$ and $6 \mathrm{dS}$ transects, respectively. The salt used was calcium chloride $\left(\mathrm{CaCl}_{2}\right)$.

Each transect consisted of seven rows of green beans crop, 70 $\mathrm{cm}$ apart and plants in each row $40 \mathrm{~cm}$ apart. Before the experiment, for each transect, 12 undisturbed soil samples were collected at two different depths $(0-10$ and $20-30 \mathrm{~cm})$ to be analysed in the laboratory for texture, bulk density, and soil water retention. The water retention was determined by using the Stakman method (Stakman et al., 1969). Field capacity was assumed to correspond to the water content at a pressure head value of $-330 \mathrm{~cm}$. The average field capacity water content for each depth was assumed to represent the whole transect. A drip irrigation system was installed, consisting of fourteen dripper lines at $35 \mathrm{~cm}$ distance and a distance among drippers along each line of $30 \mathrm{~cm}$, with individual dripper discharge of $2 \mathrm{Lh}^{-1}$. The irrigation volumes were calculated according to the time-dynamics of water storage measured by a Diviner 2000 capacitance sensor. For each transect, 24 access tubes, $1 \mathrm{~m}$ apart, were installed along the middle line at $60 \mathrm{~cm}$ depth to monitor water content in the soil before and after irrigation. Diviner readings were taken at $10 \mathrm{~cm}$ depth intervals up to 60 $\mathrm{cm}$, just before and two hours after every irrigation application (every two days). The difference between the water storage at the average field capacity (in the depth-interval $0-50 \mathrm{~cm}$ ) and the storage measured just before irrigation, allowed estimation of the irrigation volumes required to bring the soil water content in the root zone, reduced because of drainage and evapotranspiration, back to the field capacity. Irrigation volumes were applied every two days. This allowed relatively stable soil water contents to be maintained close to the field capacity.

A schematic view of the experimental field, along with the monitoring grid, is shown in Figure 1.

\section{Electromagnetic induction sensors and time domain reflectometry measurements}

EMI readings in both horizontal $\left(\mathrm{EC}_{\mathrm{a}} \mathrm{H}\right)$ and vertical magnetic dipoles $\left(\mathrm{EC}_{\mathrm{a}} \mathrm{V}\right)$ configurations were taken by a Geonics EM38 device (Geonics Limited, Ontario, Canada). The EM38 operates at a frequency of $14.6 \mathrm{kHz}$ with a coil spacing of $1 \mathrm{~m}$, with an effective measurement depth of $\approx 0.75 \mathrm{~m}$ and $\approx 1.5 \mathrm{~m}$, respectively in the horizontal and vertical dipoles configurations (McNeill, 1980). Under the assumption of induction number of the device, $\mathrm{N}_{\mathrm{b} \ll 1}$, the linear model proposed by McNeil (1980) predicts the $E C_{a}$ as:

$$
\begin{aligned}
& \mathrm{EC}_{\mathrm{a}} \mathrm{H}=\int_{0}^{\infty} \varphi^{\mathrm{H}}(\mathrm{z}) \sigma_{\mathrm{b}}(\mathrm{z}) \mathrm{dz} \\
& \mathrm{EC}_{\mathrm{a}} \mathrm{V}=\int_{0}^{\infty} \varphi^{\mathrm{v}}(\mathrm{z}) \sigma_{\mathrm{b}}(\mathrm{z}) \mathrm{dz}
\end{aligned}
$$

where $\varphi^{\mathrm{H}}$ and $\varphi^{\mathrm{V}}$ are the sensitivity function of the sensor under the horizontal and vertical dipole configurations, respectively. Equation 1 makes clear the dependence of the $E C_{a}$ on the distribution of the $\sigma_{b}$ along the whole soil profile investigated by the sensor. The $E C_{a}$ measurement from EM38 is averaged over a lateral area approximately equal to the measurement depth. Thus, it should be clear that the $\sigma_{b}$ seen by the EMI in a given discrete depth-layer is different from that seen by a TDR probe in the same depth-layer, due to the different observation volumes of the two sensors. At the beginning of each measurement campaign, the sensor was nulled according to the producer's manual. Readings were taken just after each irrigation application at $1 \mathrm{~m}$ step along the central line of each transect, for a total of 24 measurements per transect per time. Taking measurements just after irrigation allowed an assumption of relatively time-stable water contents at each site over all the monitoring campaigns. Thus changes in the EM readings could be ascribed mostly to changes in salinity. Overall, fourteen EM38 measurement campaigns were carried out during the experiment, from May $27^{\text {th }}$ to July $17^{\text {th }}$.

Just after each EM38 measurement campaign, direct $\sigma_{\mathrm{b}}$ measurements in the soil layer $0-20 \mathrm{~cm}$ were taken by a TDR probe inserted vertically at the soil surface in 24 sites, each corresponding to the central point of an EM38 reading. TDR measurements were taken by using a Tektronix 1502C cable tester (Tektronix Inc., Baverton, OR, USA). This reflectometre can measure the total resistance, $Z$, of the transmission line by:

$$
Z=Z_{c} \frac{\left(1+\rho_{\infty}\right)}{\left(1-\rho_{\infty}\right)}=Z_{s}+Z_{c}
$$

where $Z_{\mathrm{s}}$ is the soil's contribution to total resistance, $Z_{\mathrm{c}}$ accounts for the contribution of the series resistance from the cable and the connector (the characteristic impedance of the transmission line)

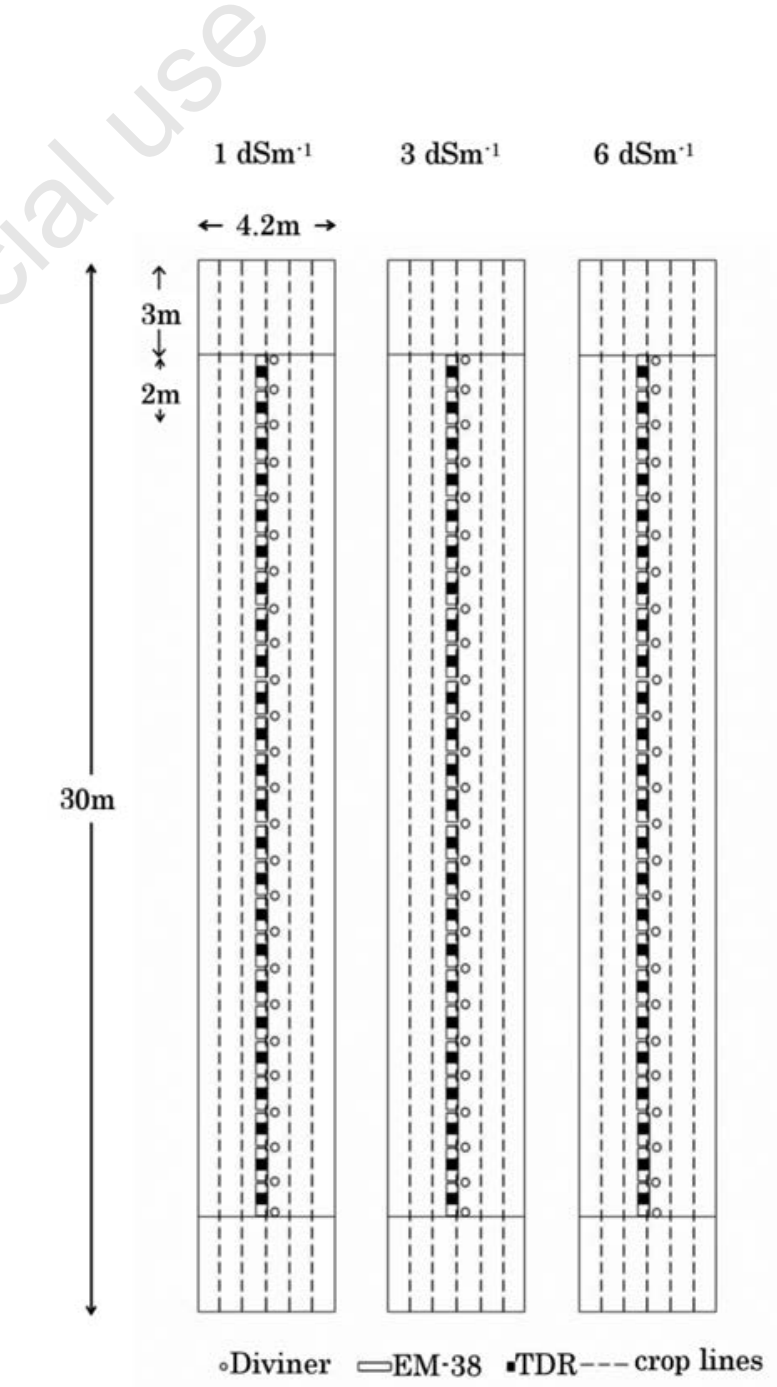

Figure 1. Schematic view of the experimental field. 
and $\rho_{\infty}$ is a reflection coefficient at a very long time, when the waveform has stabilized.

The $\sigma_{\mathrm{b}}$ at $25^{\circ} \mathrm{C}$ can be calculated as (Rhoades and van Schilfgaarde, 1976; Wraith et al., 1993):

$$
\sigma_{\mathrm{b}^{25^{\circ} \mathrm{c}}}=\frac{\mathrm{K}_{\mathrm{c}}}{\mathrm{Z}_{\mathrm{s}}} \mathrm{f}_{\mathrm{T}}
$$

where $K_{\mathrm{c}}$ is the cell constant of the TDR probe and $f_{\mathrm{T}}$ is a temperature correction factor to be used for values recorded at temperatures other than $25^{\circ} \mathrm{C}$. Both $Z_{\mathrm{c}}$ and $K_{c}$ can be determined by measuring $Z$ by TDR in solutions with known $\sigma_{b}$.

Hereafter, these $\sigma_{\mathrm{b}}$ measurements will be identified as $\sigma_{\mathrm{b}, \mathrm{TDR}}$. The TDR transmission line consisted of an antenna cable (RG58, $50 \Omega$ characteristic impedance, $200 \mathrm{~cm}$ long and with $0.2 \Omega$ connector impedance) and of three-wire probes, $20 \mathrm{~cm}$ long, $3 \mathrm{~cm}$ internal distance, and $0.3 \mathrm{~cm}$ in diameter. The TDR probe was not embedded permanently at fixed depths along the soil profile because of the interferences of metallic TDR rods with EMI readings. Only immediately after the last EM38 campaign (July $\left.17^{\text {th }}\right)$, TDR readings were taken at three different depth intervals (0-20, 20-40, 40$60 \mathrm{~cm})$. After reading at the surface $(0-20 \mathrm{~cm})$, a trench was dug up to $20 \mathrm{~cm}$ depth. TDR probes were inserted vertically for readings in the interval $20-40 \mathrm{~cm}$. Then, the trench was deepened up to 40 $\mathrm{cm}$ and readings were taken at $40-60 \mathrm{~cm}$ depth interval. $\sigma_{\mathrm{b}, \mathrm{TDR}}$ readings in this last campaign were used for calibrating the EM38 (see the EMI calibration procedure below). All the remaining fourteen data series, collected in the $0-20 \mathrm{~cm}$ layer, were used for validation of the calibrated parameters.

\section{Data analysis}

\section{Calibration of electromagnetic induction sensors by time domain reflectometry readings}

A multiple linear regression was used to find the calibration coefficients specific for a soil layer depth (Rhoades et al., 1989, 1990; Rhoades and Corwin, 1981; Triantafilis et al., 2000; Amezketa, 2006; Yao and Yang, 2010). It is a simplified form of the approach originally proposed by Rhoades and Corwin (1981) and uses only surface EMI measurements in both vertical $\left(\mathrm{EC}_{\mathrm{a}} \mathrm{V}\right)$ and horizontal $\left(\mathrm{EC}_{\mathrm{a}} \mathrm{H}\right)$ operation modes. The depth-specific calibration curves were obtained by fitting a multiple linear regression model to the $\sigma_{b}$,TDR calibration data measured within discrete depth intervals of the soil profile:

$$
\sigma_{b, E M I, d i}=\alpha_{d i}+\beta_{d i} E_{a} H+\gamma_{d i}\left(E_{a} H-E_{a} V\right)
$$

where $\sigma_{b}$,EMI,di is the bulk electrical conductivity estimated in the soil depth increment $d i\left(0-20,20-40\right.$ and 40-60 cm) from $\mathrm{EC}_{\mathrm{a}}$ readings. In the Equation $4, \alpha, \beta$ and $\gamma$ are depth-specific, empirically determined parameters. The difference $\mathrm{EC}_{\mathrm{a}} \mathrm{H}-\mathrm{EC}_{\mathrm{a}} \mathrm{V}$ was used to reduce the effect of collinearity between the $\mathrm{EC}_{\mathrm{a}} \mathrm{H}$ and $\mathrm{EC}_{\mathrm{a}} \mathrm{V}$ readings (Lesch et al., 1998).

Calibration parameters were estimated by pooling all the data into a single dataset. The $1 \mathrm{dS}, 3 \mathrm{dS}$ and $6 \mathrm{dS}$ EMI and TDR calibration data series were firstly joined in unique EMI and TDR data sets before fitting Equation 4 to measurements. Thus calibration data covered a wide range of salinity values and provided an iden- tical parameters vector for all the three transects, but still different for the three depth intervals.

\section{Validation of the calibration equation parameters}

The direct $\sigma_{\mathrm{b}, \mathrm{TDR}}$ readings - taken in the layer $0-20 \mathrm{~cm}$ in each of the 24 EMI measurement sites - were compared to the $\sigma_{b . E M I}$ estimations coming from the application of the predictive equation for the layer $0-20 \mathrm{~cm}$ to the $\mathrm{EC}_{\mathrm{a}} \mathrm{H}$ and $\mathrm{EC}_{\mathrm{a}} \mathrm{V}$ readings. To do that, the calibration parameters obtained from data of the last EM38 campaign (July $17^{\text {th }}$ ), were applied to the remaining fourteen measurement dates for translating EMI data in as many estimated 0-20 cm ob,EMI values.

As no TDR validation data were available for the deeper intervals $20-40 \mathrm{~cm}$ and $40-60 \mathrm{~cm}$, the predictive effectiveness of the calibration equations was evaluated only for the first $0-20 \mathrm{~cm}$ layer.

\section{Data filtering}

In this section we considered the issue of filtering the original spatial data series to leave out the part of the original data variability coming from small scale heterogeneities (only seen by TDR probes) and keeping only the information at a spatial scale larger than the observation volume of both the sensors, detected by both the EMI and TDR probes. To do that, we carried out a Fourier transform (FT) of the original data (an example of applications of the FT to $\sigma_{\mathrm{b}}$ data from TDR readings may be found in Coppola et al., 2011, 2016). For the sake of readability, some theoretical details are given in Appendix. After removing the higher frequencies (the small scale information) harmonics, a smoothed data series was rebuild through the Equation A5 (Appendix). The FT was applied to both the EMI and TDR data spatial series for all the measurement campaigns. The calibration and validation procedures already applied to the original data series were thus repeated for the filtered data series.

\section{Results and discussion}

\section{Calibration and validation: original data}

Figure $2 \mathrm{~A}$ shows the results of the calibration procedure applied separately for the three depth intervals 0-20, 20-40 and 40$60 \mathrm{~cm}$ at $1 \mathrm{dS}, 3 \mathrm{dS}$ and $6 \mathrm{dS}$ data.

The graphs also show the $\mathrm{EC}_{\mathrm{a}} \mathrm{H}$ and the $\mathrm{EC}_{\mathrm{a}} \mathrm{V}$ series for each of the three transects.

As for the TDR data, it may be observed that the $1 \mathrm{dS}$ data mostly overlaps at all the three depth-layers. By increasing the salinity of the irrigation water the electrical conductivity at the soil surface progressively increases in the $3 \mathrm{dS}$ and $6 \mathrm{dS}$ treatments, while deeper in the soil profile (20-40 and 40-60 cm layers) it remains approximately at the same average values observed in the $1 \mathrm{dS}$ treatment. This indirectly confirms that the irrigation water salt dynamics mostly invaded only the first depth-layer, due to both the shallow roots of the crop used and the irrigation strategy adopted, so that, at each irrigation time, irrigation provided only the water lost by evapotranspiration (for details, see the Materials and methods section). By comparing the $\mathrm{EC}_{\mathrm{a}} \mathrm{H}$ and the $\mathrm{EC}_{\mathrm{a}} \mathrm{V}$ series, a quasi-parallel behaviour may be observed in the $1 \mathrm{dS}$ and the $3 \mathrm{dS}$ treatments. This means that the EMI sensor in the two configurations is looking at the same $\sigma_{b}$ vertical distribution but weighted with different depth responses. By contrast, in the $6 \mathrm{dS}$ treatment the two signals became significantly different due to the major 
change of salinity at the soil surface. The $\mathrm{EC}_{\mathrm{a}} \mathrm{H}$ is obviously more sensitive to the increase of the salinity at the soil surface. By comparing the TDR and EMI series, it may be observed that macroscopically the $\mathrm{EC}_{\mathrm{a}} \mathrm{H}$ follows the general trend of the TDR data. This is especially apparent in the $6 \mathrm{dS}$ transect. However, by looking at the small observation scale of the TDR, in several parts of the graph decreasing TDR readings correspond to increasing EMI values and vice versa. In general, the small-scale variability revealed by TDR readings is smoothed by the set of EMI readings.

The TDR calibration data $\left(\sigma_{b}, \mathrm{TDR}\right)$ span in the range $0.25-0.75$, $0.30-1.0$ and $0.25-1.5\left(\mathrm{dSm}^{-1}\right)$ for the $1 \mathrm{dS}, 3 \mathrm{dS}$ and $6 \mathrm{dS}$, respectively. The calibration for the $1 \mathrm{dS}$ transect yields $\sigma_{b}$,EMI estimations practically overlapping for the three depths, with values included in a relatively narrow range and not able to reproduce the small
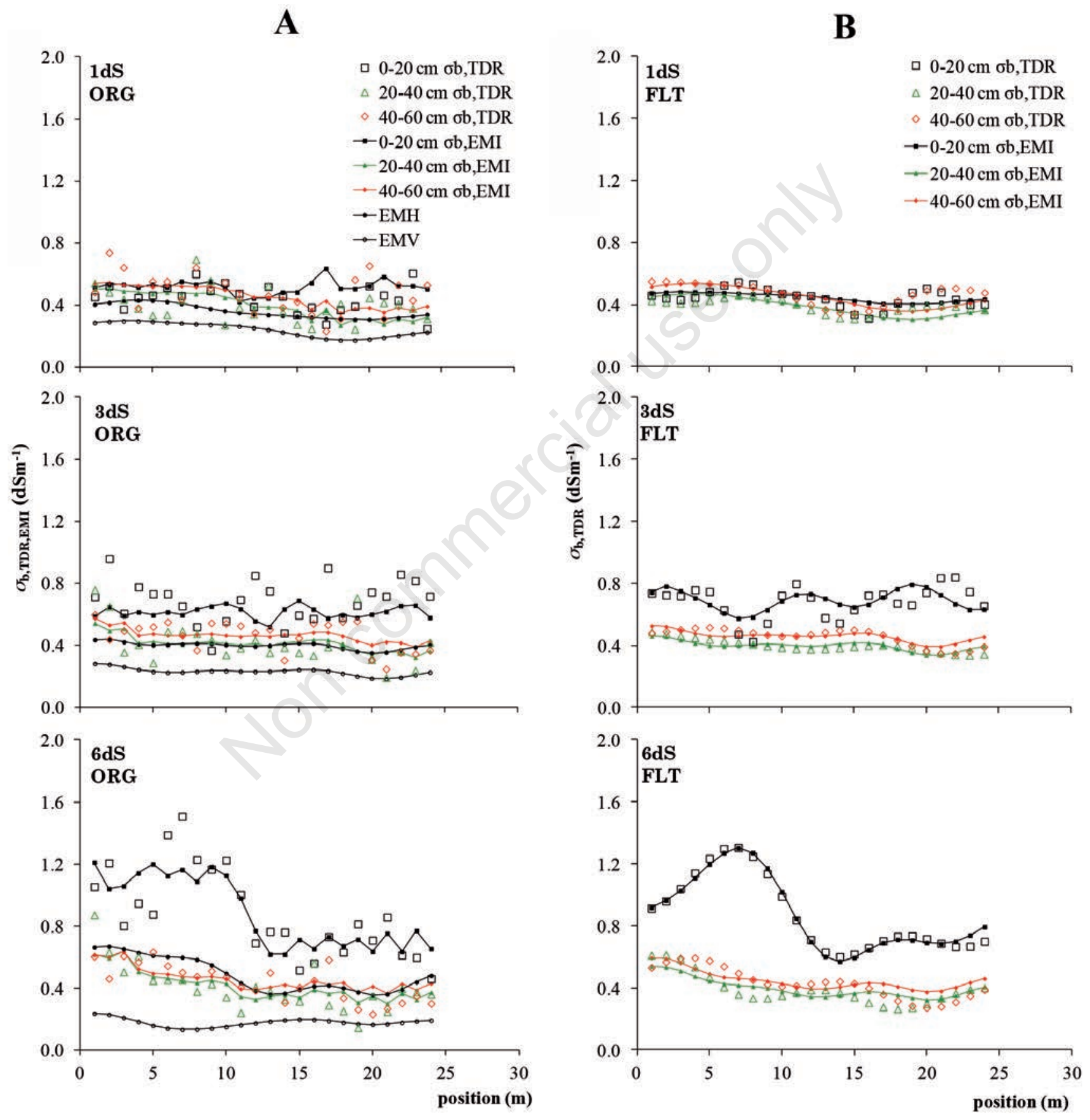

Figure 2. Space evolution of $\sigma b$,TDR measured at the three depth-layers $(0-20,20-40$ and $40-60 \mathrm{~cm})$ at the calibration time $\left(J u l y ~ 17^{\text {th }}\right)$ for the $1 \mathrm{~d} S, 3 \mathrm{~d} S$ and $6 \mathrm{dS}$ transects. The data refer to: $A$ ) the original data series (ORG); B) the filtered data series (FLT). Panel A also shows the $\mathrm{EC}_{\mathrm{a}} \mathrm{H}$ and the $\mathrm{EC}_{\mathrm{a}} \mathrm{V}$ measured at the calibration time. 
scale (local scale) fluctuations observed by TDR. The ob,EMI estimations for the $6 \mathrm{dS}$ transect reproduce the spatial (both horizontal and vertical) dynamic observed by TDR. A midway situation was observed for the $3 \mathrm{dS}$ case. It is worth noting that readings in the $6 \mathrm{dS}$ survey embrace the whole range of values observed in all three transects.

The calibration parameters $\alpha, \beta$, and $\gamma$ (see Equation 4) for the three depth intervals and the three transects are reported in Table 1 and are labelled as ORG data (to mean original data).

\section{Validation}

The predictive effectiveness of these calibration parameters was evaluated by comparing the $\sigma_{\mathrm{b}}$ estimated from EMI readings $\left(\sigma_{b}\right.$, EMI $)$ to the $\sigma_{b}$,TDR validation data taken in the layer $0-20 \mathrm{~cm}$ for the fourteen data series ( 24 readings per transect per data series, a total of 1008 data) not used in the calibration procedure.

The graphs in the Figure 3 show the ratio of the original (ORG - full symbols and lines) $\sigma_{b}$,EMI to the $\sigma_{b}, T D R$, both averaged over the fourteen monitoring dates. Figure 4A compares the variances of the original (ORG) $\mathrm{EC}_{\mathrm{a}} \mathrm{H}$ and $\sigma_{\mathrm{b}, \mathrm{TDR}}$ data series observed during the experiment. In the Figures 3 and 4A, the TDR data refer to the 0-20 cm depth-layer.

The aim of these graphs is to provide a synthetic evaluation of the capability of the $\sigma_{b}$,EMI estimations to reproduce the average behaviour and the pattern of variability observed by TDR in the shallow $0-20 \mathrm{~cm}$ layer explored by the roots.

The average ratio for the original data (ORG) takes values quite close to one in all the three transects, thus suggesting that in each site and in each of the three transects the EMI estimations may be effectively used to represent the average (over time) behaviour observed by the TDR.

The same cannot be said for the variance. As expected, the TDR variance is on average one-two orders of magnitude higher than the EM38 variance. In general, increasing salinity levels reduce the variance differences. As for the $1 \mathrm{dS}$, the ratio between the variances tends to remain approximately constant in the first half of the period considered. After the $30^{\text {th }}$ day of observation, the TDR variance remains quite stable while the EM38 variance tends to increase regularly, thus inducing a divergence reaching its maximum on the last monitoring day, that is the data series used for calibration (17 July). A much more irregular behaviour of the two variances may be observed in the $3 \mathrm{dS}$ case, where the ratio between the two variances is changing continuously and intermittently. The best situation was found for the $6 \mathrm{dS}$ transect, where the two variances differed for less than one order of magnitude and the trend of the $\mathrm{EC}_{\mathrm{a}} \mathrm{H}$ variance resembled more closely that of the TDR variance. On the whole, a clear temporal dynamics (more or less irregular) of the variances was observed during the monitoring campaigns.

The graphs in the Figure 5A-C show the scatter plots of the $\sigma_{b, E M I}$ estimations in the $0-20 \mathrm{~cm}$ layer $v s$ the $\sigma_{b}$,TDR data for the three treatments $1 \mathrm{dS}(\mathrm{a}), 3 \mathrm{dS}$ (b) and $6 \mathrm{dS}$ (c). For the sake of brevity, the graphs are reported only for selected days (25, 28 June; 1, 9, 12 July).

The $1 \mathrm{dS}$ data suggest that the TDR probes see variability in the 0-20 cm layer, which is not detected by the EMI sensor. This was expected by looking at the corresponding calibration, mostly insensitive to the $\sigma_{b}$,TDR fluctuations. As for the $3 \mathrm{dS}$ transect, calibration proved to reproduce better the TDR data dynamics. And yet, an unacceptable data scattering was observed, with the EMI still insensitive to the variability observed in the TDR data. The $\sigma_{b, T D R}$ data varies in the range $0.25-1.0$ while the EMI data remain mostly confined in the range $0.5-0.6$. Relatively better validation results were observed for the $6 \mathrm{dS}$ transect, with data more regularly distributed around the 1:1 line (except for the 9 July), thus indicating acceptable accuracy, but still with a relatively large scatter of the data, which may partly come from different noises in the TDR and EMI data.

In general, a decreasing systematic error with the salinity level was observed in the three plots.

Table 1. Calibration parameters obtained by fitting the dataset of the last measurement campaign (July $17^{\text {th }}$ ) for the $\sigma_{b, E M I}$ data series and for the three depth intervals.

\begin{tabular}{cccccc} 
& \multicolumn{5}{c}{ Calibration parameters } \\
ORG data & $0-20$ & 0.315 & -0.091 & 1.961 & $\mathbb{R}^{2}$ \\
& $20-40$ & -0.099 & 1.728 & -1.082 & 0.64 \\
& $40-60$ & 0.051 & 1.438 & -0.968 & 0.36 \\
FLT data & $0-20$ & 0.278 & -0.198 & 2.371 & 0.93 \\
& $20-40$ & 0.056 & 1.348 & -0.843 & 0.59 \\
& $40-60$ & 0.041 & 1.471 & -0.984 & 0.50 \\
\hline
\end{tabular}

$\mathrm{ORG}$, original data; FLT, filtered data.
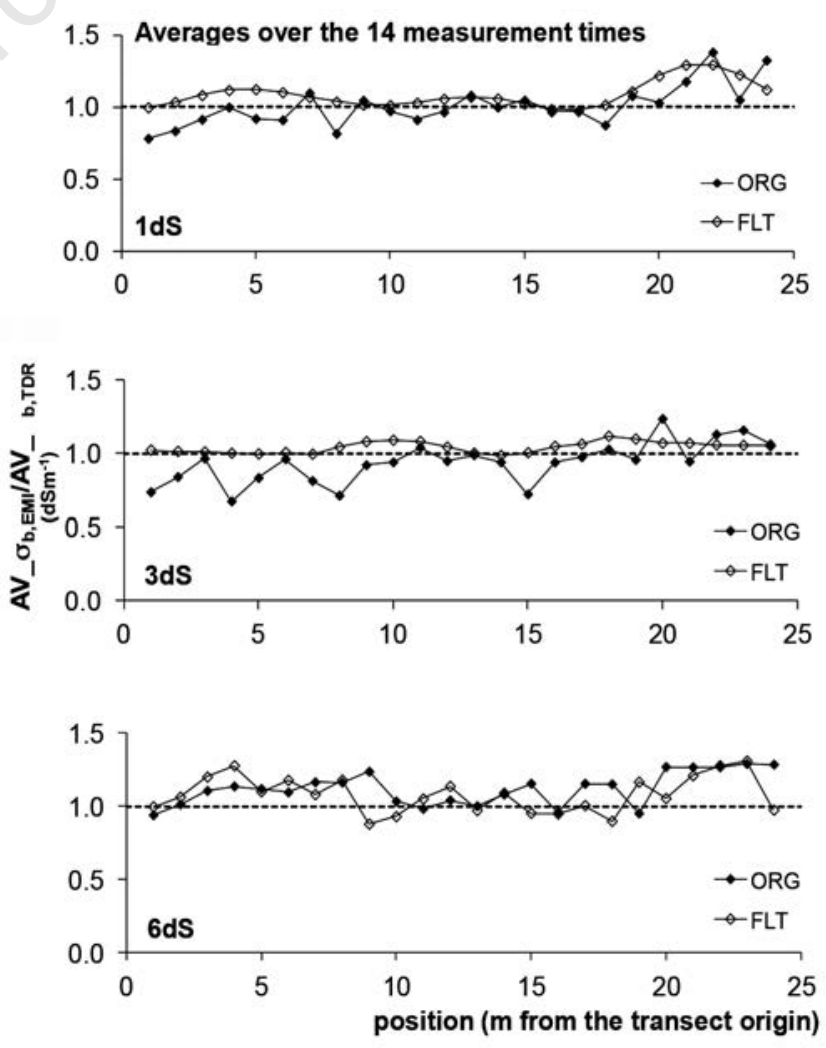

Figure 3. Ratio of the $\sigma_{b, E M I}$ to the $\sigma_{b}, \mathrm{TDR}$, both averaged over the fourteen monitoring dates, for the $0-20 \mathrm{~cm}$ depth layer. The graphs refer both to the original (ORG) and filtered data (FLT). 


\section{Calibration and validation: filtered data}

\section{Filtering}

In this section, both the calibration and validation steps so far carried out on the original data will also be applied to the filtered data series. The analysis focused on the lower frequencies (larger spatial scales), which were identified once we determined the power spectral density of each data series (data not shown). The data were filtered by retaining only the portion of the data series in the lower frequency region of the spectra, which emphasizes the component of the information that is shared by the two data series.
Equation A5 in Appendix is central in the filtering approach we used in our research. It can be used to reconstitute a smoothed data series by retaining selected harmonics only (e.g., low-frequency harmonics) and omitting the remainder of the original data signal.

Figure $6 \mathrm{~A}-\mathrm{C}$ reports the results of the filtering for the $\mathrm{EC}_{\mathrm{a}} \mathrm{H}$, $\mathrm{EC}_{\mathrm{a}} \mathrm{V}$ and TDR calibration data series (17 July series) for all the three treatments. The results for all the remaining data series largely reproduced the shape observed for the calibration data series and for the sake of brevity are not shown here.

According to the spectral analysis, in all the cases the information on the predominant portion of the EMI data series was contained in the first three harmonics for the $1 \mathrm{dS}$ and the $6 \mathrm{dS}$ data
A

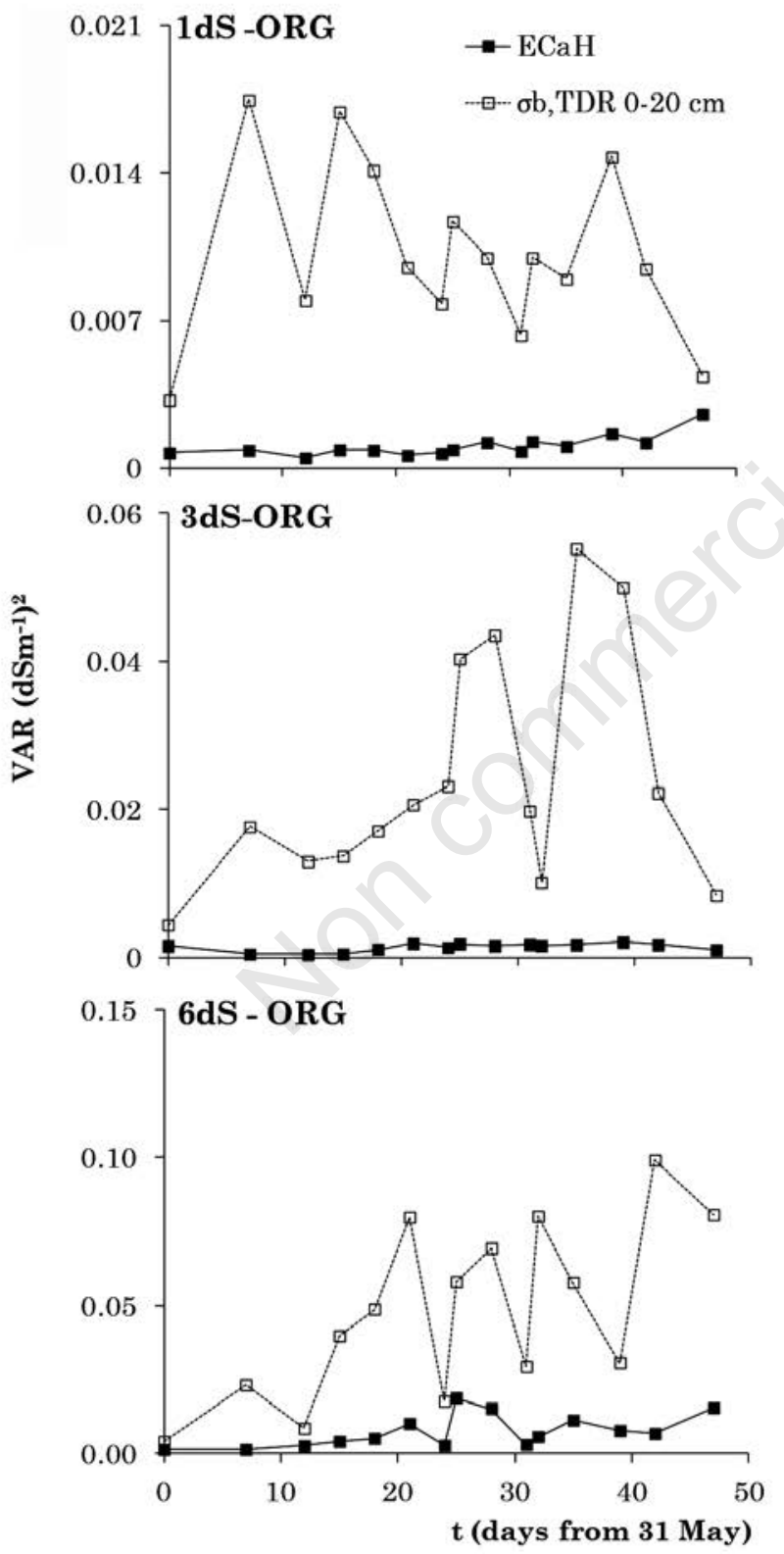

B
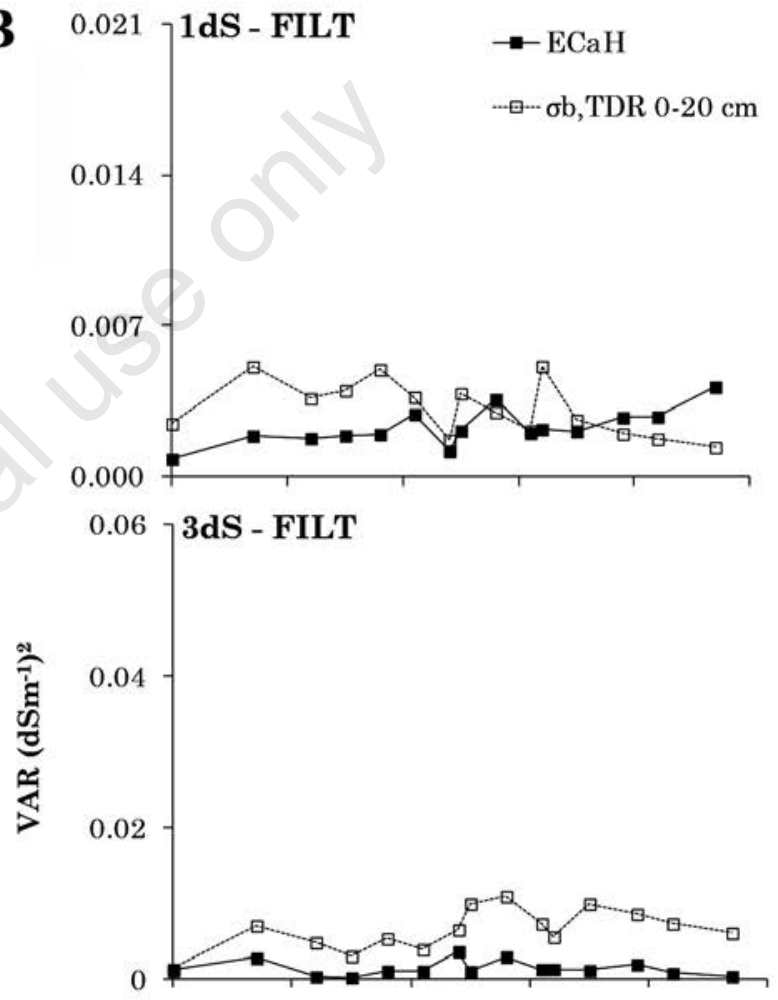

0.15

6dS - FILT

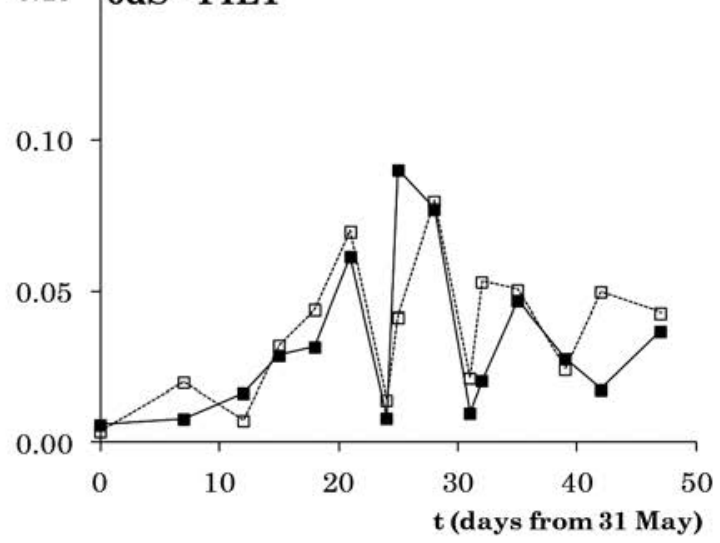

Figure 4. Comparison between the variances of the ECaH and $\sigma_{\mathrm{b}, \mathrm{TDR}}$. Data series refer to the 0-20 cm depth-layer. The graphs in panels (A) and (B) refer respectively to the original (ORG) and the filtered (FILT) data series. 

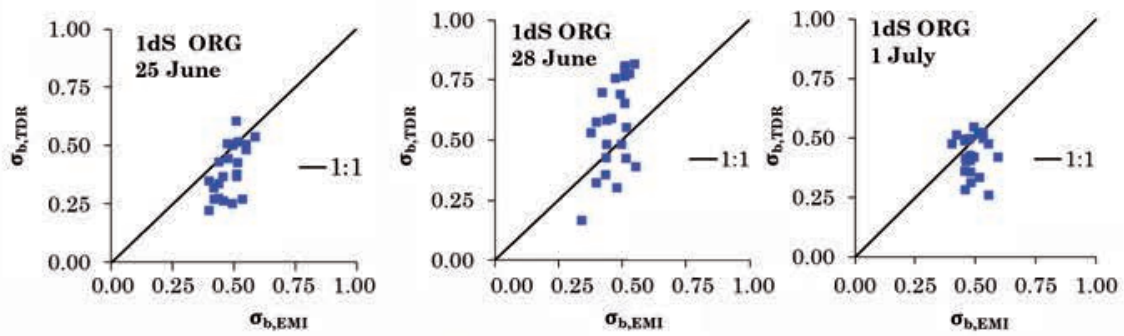

A
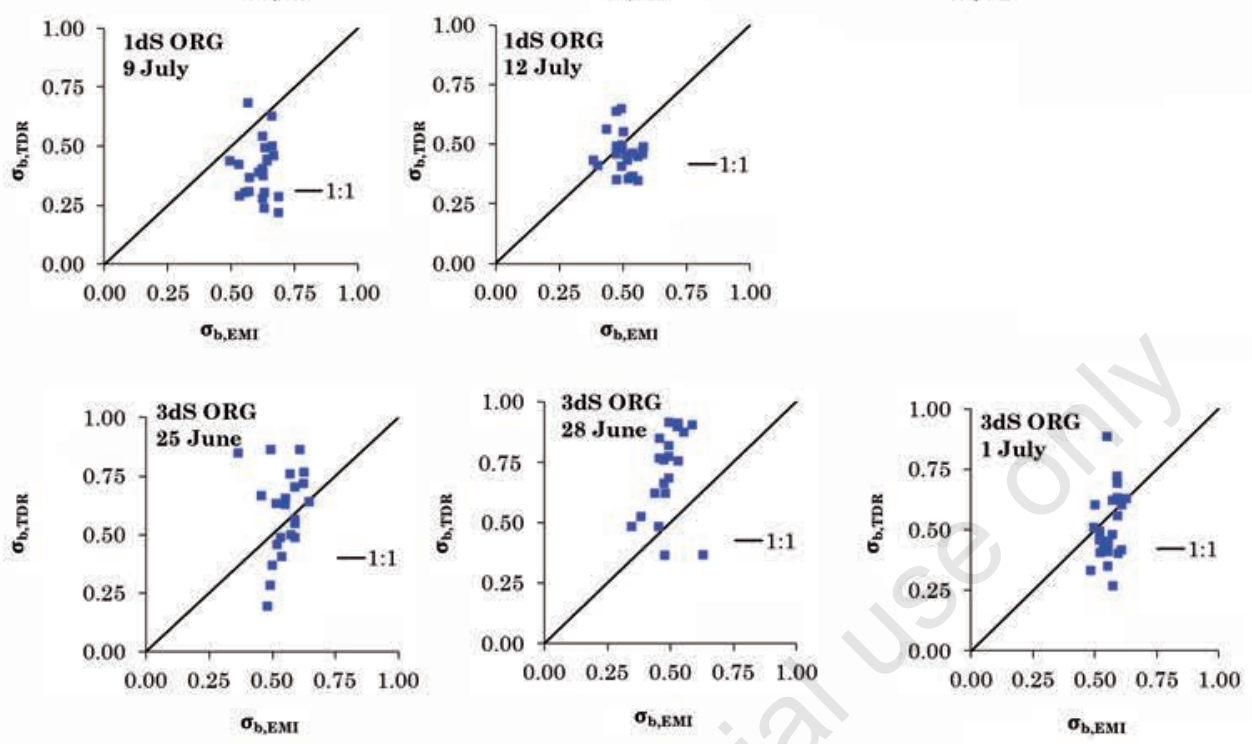

B
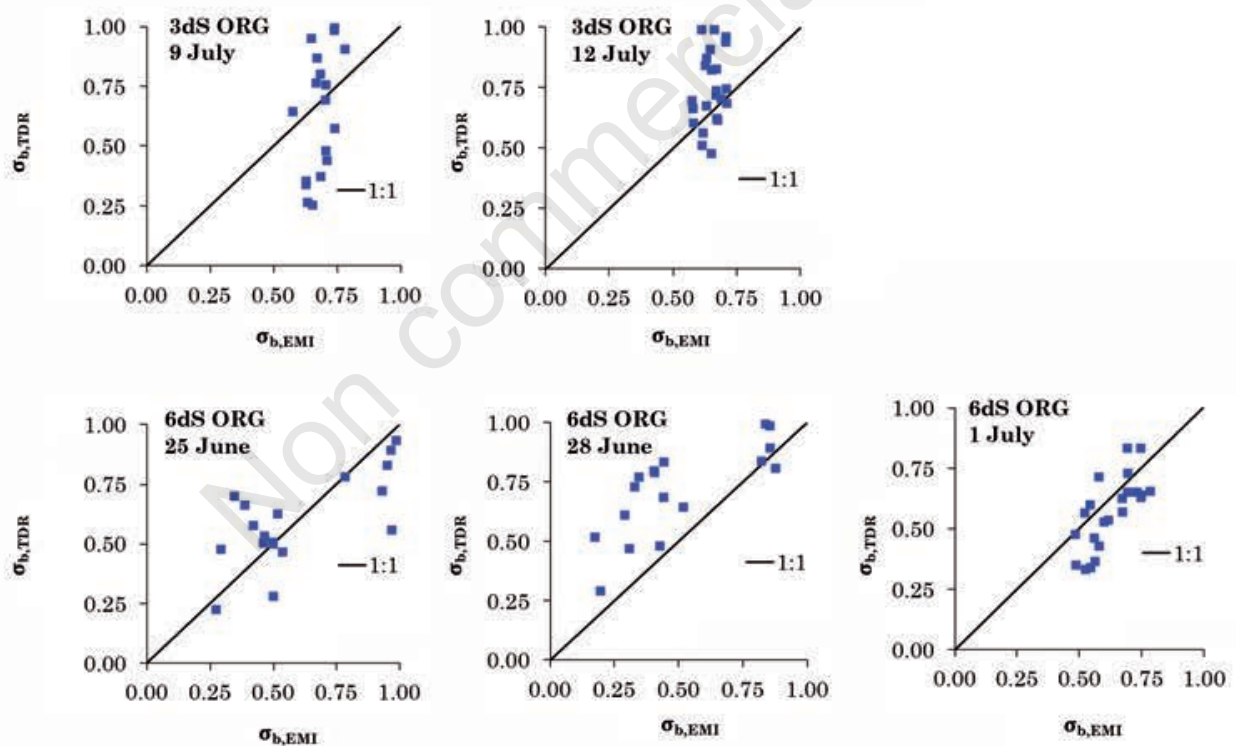

C
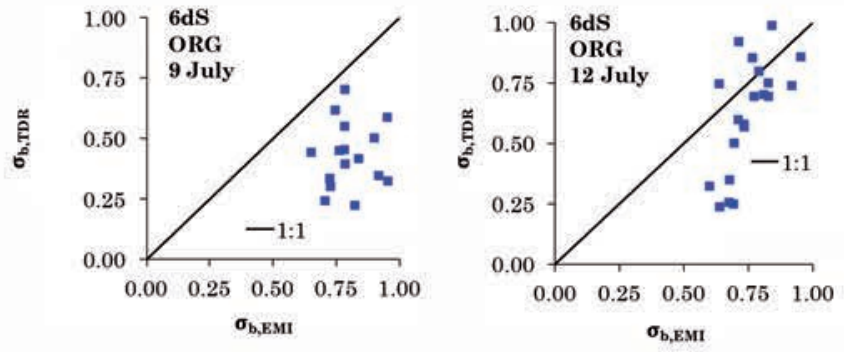

Figure 5. Scatter plots of the $\sigma_{\mathrm{b}, \mathrm{EMI}}$ estimations in the $0-20 \mathrm{~cm}$ layer $v s$ the $\sigma_{\mathrm{b}, T D R}$ data for the three treatments $1 \mathrm{dS}(\mathrm{A}), 3 \mathrm{dS}$ (B) and 6dS (C). The graphs refer to the original data (ORG) and reported for selected days (25, 28 June; 1, 9, 12 July). 
series, and in the first four harmonics for the $3 \mathrm{~d} S$ data series. Six, five and three harmonics were necessary to build back the predominant TDR signal for the $1 \mathrm{dS}$, the $3 \mathrm{dS}$ and the $6 \mathrm{dS}$ data series, respectively. Obviously, the removed high frequency signal was calculated as the sum of the remaining harmonics. The higher number of harmonics necessary to build back the TDR signal may be explained by a significant multi-scale variability observed in the TDR data series compared to the EMI data series. As previously mentioned, only in the $6 \mathrm{dS}$ case the predominant high-variance TDR signal was enclosed in the first three harmonics, like for the $\mathrm{EC}_{\mathrm{a}} \mathrm{H}$ signal. What's more, as may be observed in Figure $6 \mathrm{C}$, the $\mathrm{EC}_{\mathrm{a}} \mathrm{H}$ and the TDR signals are looking at the same predominant pattern of variability at a scale of about $10 \mathrm{~m}$, with an evident inphase cycling. This is not completely verified for the $1 \mathrm{dS}$ and the $3 \mathrm{dS}$ transects, where the two signals are partly cycling in opposition, where high $\mathrm{EC}_{\mathrm{a}} \mathrm{H}$ values may correspond to low TDR values and vice versa. To us, this behaviour highlights the strength of the information contained in the $6 \mathrm{dS}$ data series, observed and discussed in the previous section. The ability to see the full range of soil salinity variations, a high signal variance, a low noise and the in-phase $\mathrm{EC}_{\mathrm{a}} \mathrm{H}$ and TDR signals make the $6 \mathrm{dS}$ data appropriate for a more robust calibration and more effective predictions. This should be used as a criterion to select data series to be used for calibration of EMI sensors.

\section{Calibration}

After filtering, a new EMI calibration was carried out again by using Equation 4. Now the data to be used in the regression equation were the filtered $\mathrm{EC}_{\mathrm{a}} \mathrm{H}, \mathrm{EC}_{\mathrm{a}} \mathrm{V}$ and $\mathrm{TDR}$ data series of the last measurement campaign (17 July). Figure 2B reports the calibration results for the filtered data for the three treatments.

\section{Validation}

Validation was carried out by using the filtered data series for all the remaining fourteen monitoring campaigns. In all the figures, the data series coming from the filtering were labelled as FLT (to mean filtered data).

The ratio of the filtered (FLT) $\sigma_{b}$,EMI to the $\sigma_{b}$,TDR and the variances are respectively plotted in the graphs of Figure 3 (empty symbols and lines) and Figure 4B; it may be immediately realized that removing the effects of the small scale heterogeneities from the TDR readings (FLT data) improves significantly the comparison between EMI and TDR data. Now, the $\sigma_{b}, E M I / \sigma_{b}, T D R$ ratio lies quite regularly around a value of 1 . The improvement is especially apparent for the $1 \mathrm{dS}$ and the $3 \mathrm{dS}$ transects (see also comparison between Figures 5 and 7).

Figure $4 \mathrm{~B}$ compares the variances of the $\mathrm{EC}_{\mathrm{a}} \mathrm{H}$ and $\sigma_{\mathrm{b}, \mathrm{TDR}}$ of the filtered data series for all the fifteen monitoring campaigns and for the three transects. Again, TDR data refer to the $0-20 \mathrm{~cm}$ layer. Compared to the graphs of variance in Figure 4B, where the variances between $\mathrm{EC}_{\mathrm{a}} \mathrm{H}$ and $\sigma_{\mathrm{b}, \mathrm{TDR}}$ original data differed even for more than one order of magnitude, removing the small scale information from the data shifted the variances in the same range of values, with a time evolution of variances now almost overlapping. Obviously, cutting high frequency (small scale) information from the original data had especially effects on the decrease of TDR variances, due to its relatively higher local scale information content, while only minor effects were observed on the $\mathrm{EC}_{\mathrm{a}} \mathrm{H}$ variances, as EMI readings mostly smoothes the local scale information.

Quantitative evaluation of the filtered $\sigma_{b}$,EMI predictions are shown in the Table 1.

The scatter plots for the filtered data are reported only for
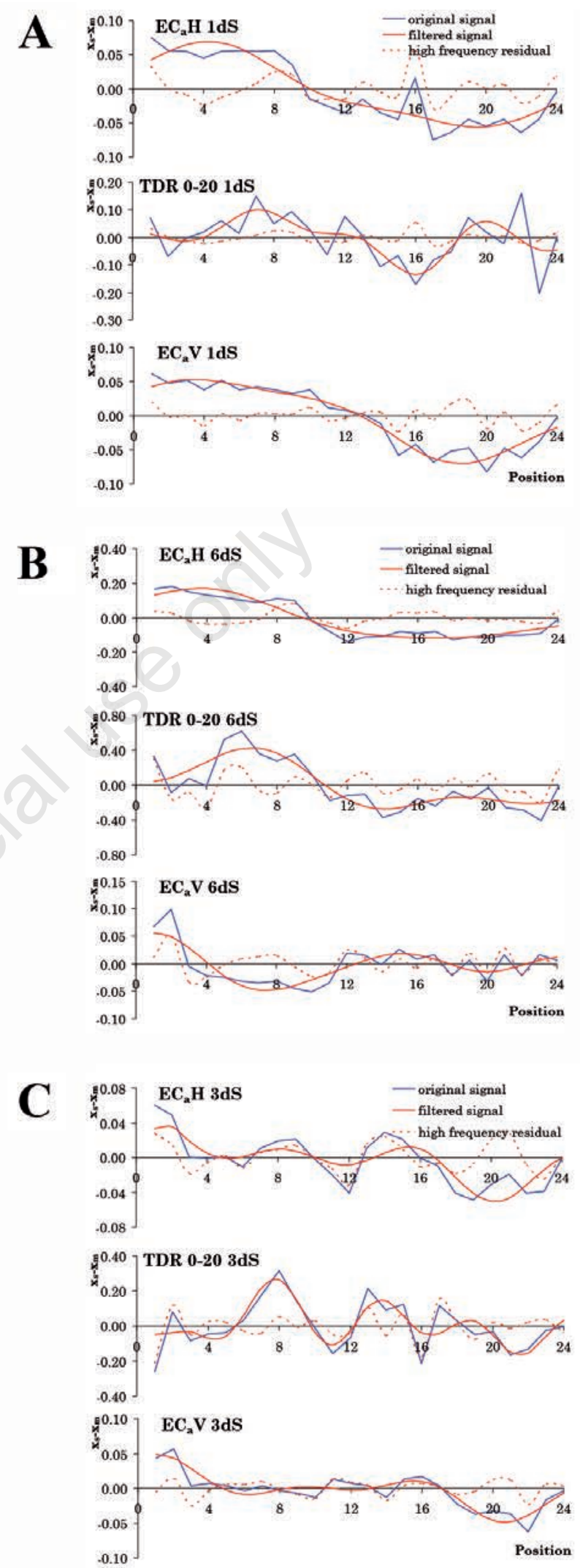

Figure 6. Original and filtered data series for the ECaH, ECaV and TDR at $0-20 \mathrm{~cm}$ depth for the $1 \mathrm{dS}(\mathrm{A})$, the $3 \mathrm{dS}(\mathrm{B})$ and the 6dS (C). The graphs refer only to the calibration data series (17 July). 

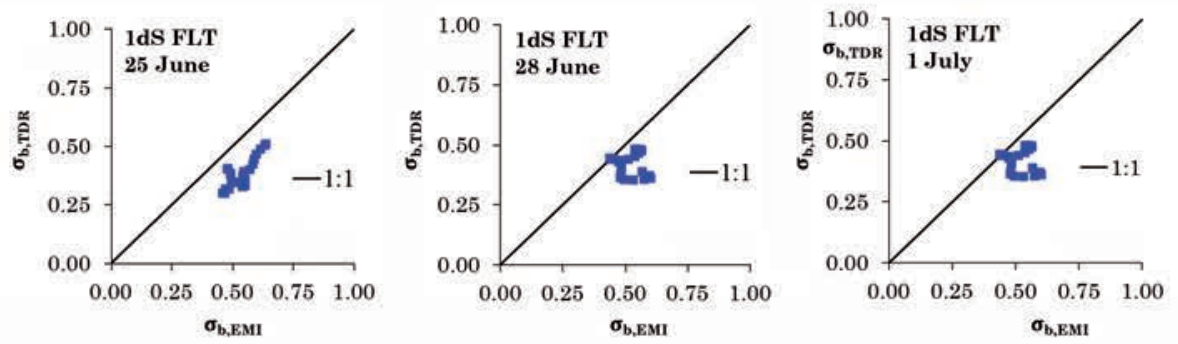

$\mathbf{A}$
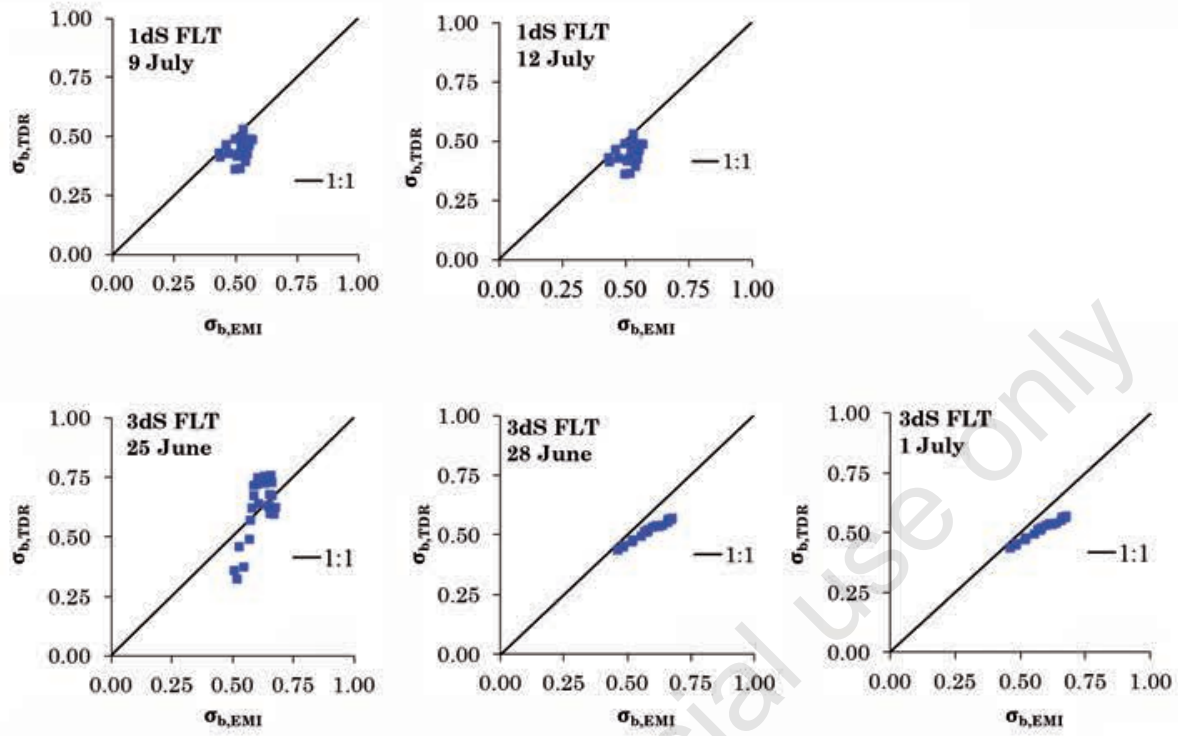

B
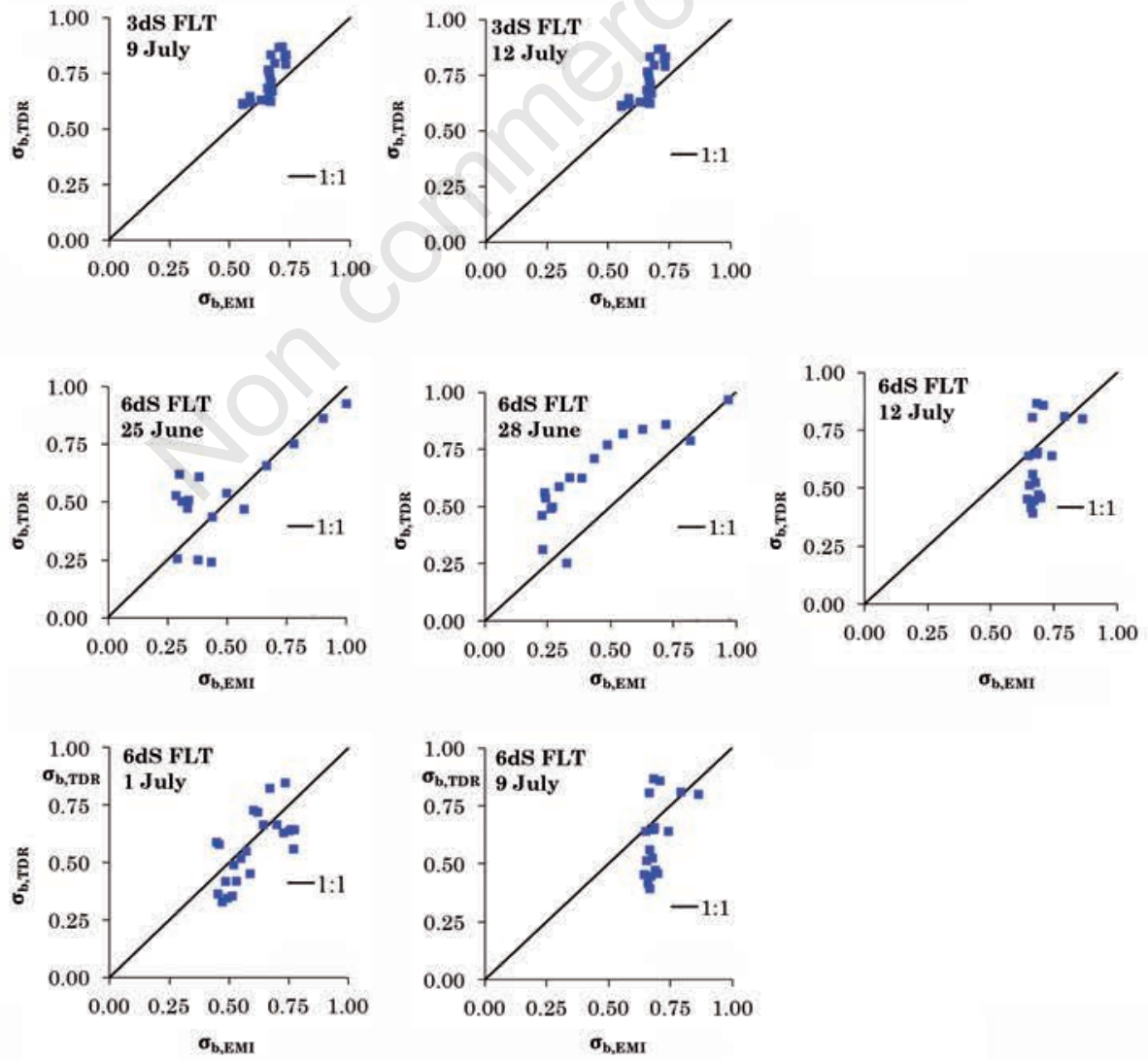

Figure 7. Scatter plots of the $\sigma \mathrm{b}, \mathrm{EMI}$ estimations in the $0-20 \mathrm{~cm}$ layer vs the $\sigma_{\mathrm{b}, \mathrm{TDR}}$ data for the three treatments $1 \mathrm{dS}(\mathrm{A}), 3 \mathrm{dS}(\mathrm{B})$ and 6dS (C). The graphs refer to the filtered data (FLT) and reported for selected days (25, 28 June; 1, 9, 12 July). 
selected days $(25,28$ June; 1, 9, 12 July) in the Figure 7A-C. The plots for the $1 \mathrm{dS}$ and the $3 \mathrm{dS}$ show a considerable decrease of the scatter. This is only partly evident in the $6 \mathrm{dS}$ transect because of the natural higher variability of electrical conductivity at higher salinity levels, so that data filtering only produced minor improvements in the scatter than for the other transects. This may also explain the behaviour observed in the Figure 3, where the $\sigma_{b, E M I} / \sigma_{b}, \mathrm{TDR}$ ratio for the $6 \mathrm{dS}$ transect showed only minor improvements compared to the $1 \mathrm{dS}$ and the $3 \mathrm{dS}$ transects.

\section{Conclusions}

The effects of the different observation volume of the EMI and TDR sensors on the calibration of the EMI sensor and on the consequent validation of the prediction effectiveness of the calibrated parameters were investigated. After examining the different patterns of variability of the original EMI and TDR data series, a classical Fourier's filtering technique was applied to remove the high frequency part (at smaller spatial scale) of the original data variability, which, due to the different observation volume, was shown to be the main source of dissimilarity between the patterns of variability of the two datasets. Thus, calibration focused only on the lower frequency information that is the information at a spatial scale larger than the observation volume of the sensors. Being detected by both the sensors, the latter made the two data series actually comparable. By this analysis, we showed and quantified at which degree the variability of the set of TDR readings came from a combination of local and larger scale heterogeneities and how EMI readings smoothed the small-scale variability seen by TDR probes.

An important finding was that the robustness of the information coming from the $6 \mathrm{dS}$ transect came, besides the fact that the $6 \mathrm{dS}$ survey included the whole range of values measured in all the three transects, from a close correspondence between the EMI and TDR variability patterns which were not observed in the other transects. The EMI and the TDR data series were characterized by the same predominant pattern of variability at a scale of about $10 \mathrm{~m}$, with an apparent in-phase cycling. This implicitly allowed to find some crucial characteristics that a data series have to include for a more robust calibration and more effective predictions: i) the ability to see the full range of soil salinity variations; ii) a high signal variance; iii) a low noise; iv) in-phase cycling of $\mathrm{EC}_{\mathrm{a}} \mathrm{H}$ and TDR predominant signals. These characteristics should be used as criteria to select data series to be used for calibration of EMI sensors.

In general, the filtering of the original data series had the effect of making the variability pattern observed by the TDR sensors similar to that observed by an EMI sensor in all the three transects. Overall, this demonstrates that the differences frequently observed the pattern of variability of the two sensor readings have mostly to be ascribed to the effect of small-scale heterogeneities, while the general pattern remains almost unchanged at larger scale.

\section{References}

Amezketa E. 2006. An integrated methodology for assessing soil salinization, a pre-condition for land desertification. J. Arid Environ. 67:594-606.

Borchers B., Uram T., Hendrickx J.M.H. 1997. Tikhonov regularization of electrical conductivity depth profiles in field soils. Soil Sci. Soc. Am. J. 61:1004-9.

Cook P.G., Walker G.R. 1992. Depth profiles of electrical conductivity from linear combinations of electromagnetic induction measurements, Soil Sci. Soc. Am. J. 56:1015-22.

Coppola A., Chaali N., Dragonetti G., Lamaddalena N., Comegna A. 2015. Root uptake under non-uniform root-zone salinity. Ecohydrology 8:1363-79.

Coppola A., Comegna A., Dragonetti G., Dyck M., Basile A., Lamaddalena N., Comegna V. 2011. Solute transport scales in an unsaturated stony soil. Adv. Water Resour. 34:747-59.

Coppola A., Smettem K., Ajeel A., Saeed A., Dragonetti G., Comegna A, Lamaddalena N., Vacca A. 2016. Calibration of an EMI sensor by TDR data to monitor root-zone electrical conductivity under saline water irrigation: filtering data to account different sensor observation volumes. Eur. J. Soil Sci. 67:737-48

Corwin D.L., Rhoades J.D. 1982. An improved technique for determining soil electrical conductivity-depth relations from above-ground electromagnetic measurements. Soil Sci. Soc. Am. J. 46:517-20.

Corwin D.L., Rhoades J.D. 1984. Measurement of inverted electrical conductivity profiles using electromagnetic induction. Soil Soil Sci. Soc. Am. J. 48:288-91.

Deidda G.P., Bonomi E., Manzi C. 2003. Inversion of electrical conductivity data with Tikhonov regularization approach: some considerations. Ann. Geophys. 46:549-58.

Deidda G.P., Fenu C., Rodriguez G. 2014. Regularized solution of a nonlinear problem in electromagnetic sounding. Inverse Probl. 30:125014.

Heimovaara T.J., Focke A.G., Bouten W., Verstraten J.M. 1995. Assessing temporal variations in soil water composition with time domain reflectometry. Soil Sci. Soc. Am. J. 59:689-98.

Hendrickx J.M.H., Borchers B., Corwin D.L., Lesch S.M., Hilgendorf A.C., Schlue J. 2002. Inversion of soil conductivity profiles from electromagnetic induction measurements: theory and experimental verification. Soil Sci. Soc. Am. J. 66:673-85.

Lesch S.M., Rhoades J.D., Herrero J. 1998. Monitoring for temporal changes in soil salinity using electromagnetic induction techniques. Soil Sci. Soc. Am. J. 62:232-42.

Lesch S.M., Rhoades J.D., Lund L.J., Corwin D.L. 1992. Mapping soil salinity using calibrated electromagnetic measurements. Soil Sci. Soc. Am. J. 56:540-8.

Mallants D., Vanclooster M., Toride N., Vanderborght J., van Genuchten M.T., Feyen J. 1996. Comparison of three methods to calibrate TDR for monitoring solute movement in undisturbed soil. Soil Sci. Soc. Am. J. 60:747-54.

McNeill J.D. 1980. Electromagnetic terrain conductivity measurement at low induction numbers. Geonics Limited Ontario, Canada.

Nadler A., Frenkel H. 1980. Determination of soil solution electrical conductivity from bulk soil electrical conductivity measurements by the four-electrode method. Soil Sci. Soc. Am. J. 44:1216-21.

Oberdörster C., Vanderborght J., Kemna A., Vereecken H. 2010. Investigating preferential flow processes in a forest soil using time domain reflectometry and electrical resistivity tomography. Vadose Zone J. 9:350-61.

Rhoades J.D., Corwin D.L. 1981. Determining soil electrical conductivity-depth relations using an inductive EM soil conductivity meter. Soil Sci. Soc. Am. J. 45:255-60.

Rhoades J.D., Manteghi N.A., Shouse P.J., Alves W.J. 1989. Soil electrical conductivity and soil salinity: new formulations and calibrations. Soil Sci. Soc. Am. J. 53:433-9.

Rhoades J.D., Oster. J.D. 1986. Solute content. In: A. Klute (Ed.), Methods of soil analysis. Part 1. 2nd ed. Agron. Monogr. 9. ASA and SSSA, Madison, WI, USA, pp. 985-1006. 
Rhoades, J.D., Shouse P.J., Alves W. J., Nahid A. Manteghi, and Lesch S.M. 1990. Determining soil salinity from soil electrical conductivity using different models and estimates. Soil Sci. Soc. Am. J. 54:1:46-54.

Rhoades J.D., van Schilfgaarde J. 1976. An electrical conductivity probe for determining soil salinity. Soil Sci. Soc. Am. J. 40:647-51.

Robinson D.A., Jones S.B., Wraith J.M., Or D., Friedman S.P. 2003. A review of advances in dielectric and electrical conductivity measurement in soils using time domain reflectometry. Vadose Zone J. 2:444-75.

Severino G., Comegna A., Coppola A., Sommella A., Santini A. 2010. Stochastic analysis of a field-scale unsaturated transport experiment. Adv. Water Resour. 33:1188-98.

Slater L., Binley A., Daily W., Johnson R. 2000. Cross-hole electrical imaging of a controlled saline tracer injection. J. Appl. Geophys. 44:85-102.

Slavich P.G., Petterson, G.H. 1990. Estimating average rootzone salinity from electromagnetic induction (EM-38) measurements. Soil Res. 28:453-63.

Stakman W.P., Valk G.A., van der Harst G.G. 1969. Determination of soil moisture retention curves, I. 3rd revised ed. Institute for Land and Water Management Research, Wageningen, the Netherlands.

Sudduth K.A., Kitchen N.R., Bollero G.A., Bullock D.G., Wiebold W.J. 2003. Comparison of electromagnetic induction and direct sensing of soil electrical conductivity. Agron. J. 95:472-82.

Triantafilis J., Laslett G.M., McBratney A.B. 2000. Calibrating an electromagnetic induction instrument to measure salinity in soil under irrigated cotton. Soil Sci. Soc. Am. J. 64:1009-17.

Wraith J.M., Comfort S.D., Woodbury B.L., Inskeep W.P. 1993. A simplified waveform analysis approach for monitoring solute transport using time-domain reflectometry. Soil Sci. Soc. Am. J. 57:637-42.

Yao R., Yang J. 2010. Quantitative evaluation of soil salinity and its spatial distribution using electromagnetic induction method. Agric. Water Manage. 97:1961-70.

Zhu Q., Lin H.S., Doolittle J. 2010. Repeated electromagnetic induction surveys for improving soil mapping in an agricultural landscape. Soil Sci. Soc. Am. J. 74:1763-74. 